\title{
Novel COVID-19 Intersections with Dentistry: Approaches to protection
}

\author{
Silvia Lourenço ${ }^{1}$, João-Vitor Lopes ${ }^{2}$, Gustavo-Henrique Boog ${ }^{2}$, Lucas Chinelatto ${ }^{2}$, Flavio Hojaij ${ }^{3}$ \\ ${ }^{1}$ DDS, PHD. Associate Professor - Pathology Department - Dental School - University of São Paulo, Brazil \\ ${ }^{2}$ Student - Faculty of Medicine - University of São Paulo, Brazil \\ ${ }^{3}$ MD, PHD. Associate Professor - Surgery Department - Faculty of Medicine of the University of São Paulo, Brazil
}

Correspondence:

Dental School, University of São Paulo

Av. Prof. Lineu Prestes, 2227

São Paulo - SP

CEP: 05508-000

Brazil

silvialourenco@usp.br

Lourenço S, Lopes JV, Boog GH, Chinelatto L, Hojaij F. Novel COVID-19 Intersections with Dentistry: Approaches to protection. J Clin Exp Dent. 2021;13(4):e406-11

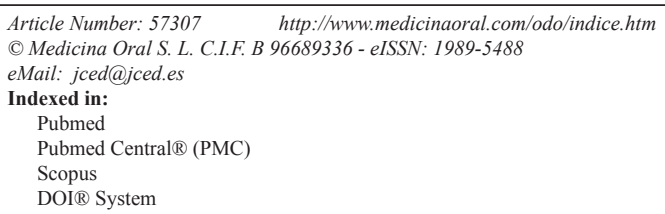

\begin{abstract}
Background: Background: COVID-19 outbreak brought many challenges to the society and to health care systems. Health care professionals in dental practices are a high-risk population, due to close contact to saliva and aerosols. Specific guidance for those professionals is essential to control disease transmission and guarantee dentist's health. Material and Methods: We performed a literature review based on online search in Pubmed, Scientific Electronic Library, Literatura Latino-Americana e do Caribe em Ciências da Saúde and Scopus databases. Included articles were fully read and analysed regarding infection control measurements, use of personal protective equipment (PPE), conditions for procedures and use of mouthrinse.

Results: Nineteen articles were added to this review. The majority of them recommended maintaining only urgency treatments, with use of rubber dam and mouthrinse before procedures.

Conclusions: The data collected suggests dental care should be performed under strict protection measures such as a pre-check questionnaire prior to any dental procedure; postponing elective dental treatments and following infection control security procedures may be strategic at this point. The use of adequate PPE for procedures is recommended. Supplementary measures should rise from further understanding of the pandemics.
\end{abstract}

Key words: COVID-19, dentistry, practice.

\section{Introduction}

The pandemic of the novel coronavirus-19 originated from an outbreak in Wuhan, China, has spread to all continents, and became an urgent public health challenge worldwide. Countries around the world have taken several measures to constrain the infection rates, and the recommendation of social distancing by the WHO has been followed as a public policy by most governments. Impacts on the many facets of society are still to be evaluated; activities in close inter-person contact are the most affected $(1,2)$. In Brazil the contamination is still rising at this point and thriving concerns on procedures to protect dental practitioners and to avoid cross contamination are being discussed. 
COVID-19 has been reputed as highly contagious and its transmittable forms are not fully understood. Mainly, it spreads from person to person, primarily by respiratory and saliva droplets (perdigottes), as well as through infected blood and body fluids, infected surfaces, amongst others. In this scenario, healthcare personnel at dental practices are at major risk; additionally, the risk of cross infection due to other causes is well known in the practice of dentistry. The teaching and practice of dentistry has been impacted by many manners, as Dental schools worldwide have to re approach their methods of training students and well-established professionals struggle with the many new guidelines to dental practice in private offices (1-4).

Dental Councils as well as sanitary authorities in countries around the 5 Continents have been discussing on the best forms to provide dental care with minimal impact to patients' health and the dental team. Some believe that the dental professionals are used to deal with a contaminated environment and with cross infection topic, therefore, they could also deal with COVID-19 infection issues. Others believe in reducing the routine oral and dental care to avoid contamination as a moral duty, including Brazilian health authorities, who recommended dental care limited to urgency cases (3-6).

Therefore, information, guidelines and determination of strict protocols to control infections are important tools to aid dental practitioners, dental nurses, tutors and students to avoid hesitant measures and vulnerabilities for both professionals and patients (1-3).

We herein revise the main publications on COVID-19 to understand the boundaries between COVID-19 and the practice of dentistry.

\section{Material and Methods}

Literature review was based on online search in PubMed from National Center for Biotechnology (NCBI), Scientific Electronic Library Online (Scielo), Literatura
Latino-Americana e do Caribe em Ciências da Saúde (LILACS) and Scopus databases. The following terms were used in the search engine for any match in articles: ((COVID) OR (CORONAVIRUS) OR (SARS-COV-2)) AND ((DENTISTRY) OR (DENTAL) OR (PERIODONTOLOGY) OR (TONGUE) OR (GINGIVA)).

Articles included in the search comprised research, letters, reviews, editorials and internet databases if their publication was in the year of 2020 and their title was relevant to this article objectives. For the present review a reference was considered relevant if: (a) it was correlated with the COVID-19 pandemic; (b) it had an approach that directly impacted in dental practice dynamics; (c) it suggested any kind of procedures for professional to avoid SARS-CoV-2 infection (d); it suggested any way to evaluate patients admission or to protect patients in dentistry offices; (e) it had any kind of recommendation about elective procedures; (f) it made any consideration for dental practices reorganization regarding the pandemic context.

Duplicates were manually deleted. After that, all selected references were read in full extent, and added or not to the review after author consensus on its relevance. Articles that were not in English were translated using validated websites.

The references were analysed regarding the following topics: reference kind, infection control measures in the dental office, personal protective equipment (PPE) for dentists, patient evaluation methods, conditions for procedures and use of mouthrinse.

Data analysis was performed using the Google Sheets application (GOOGLE INC.).

\section{Results}

Nineteen references were added in this review (Fig. 1). Of those, 8 (42\%) were opinions, letters or short communications; 4 (21\%) were reviews; 3 (15\%) were

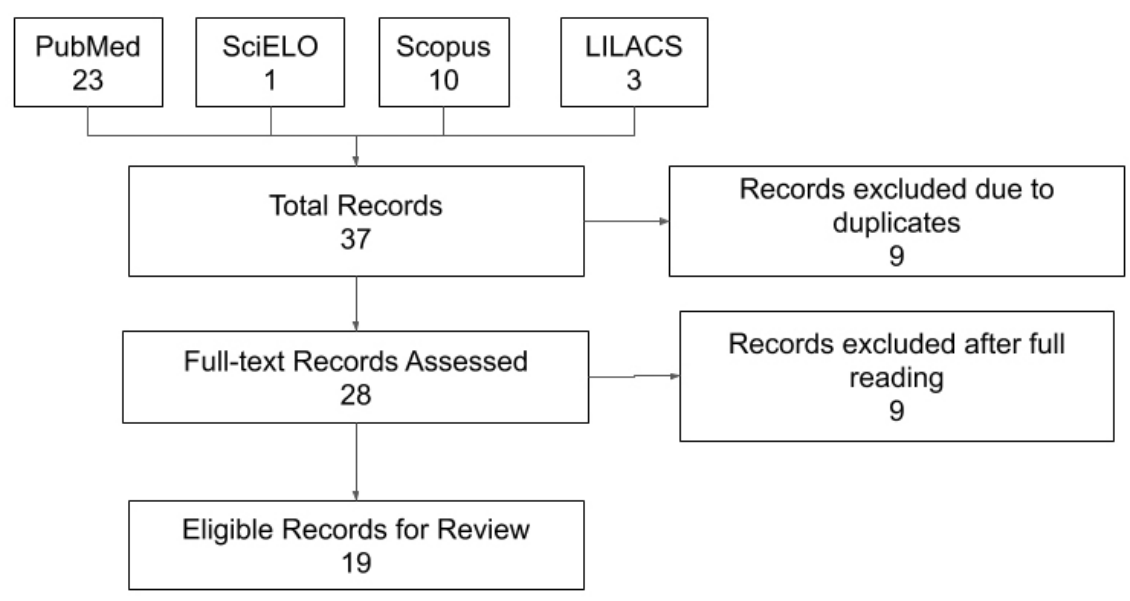

Fig. 1: Inclusion Diagram. Scielo=Scientific Electronic Library Online LILACS= Literatura Latino-Americana e do Caribe em Ciências da Saúde. 


\section{Patient Evaluation $(n=12)$}

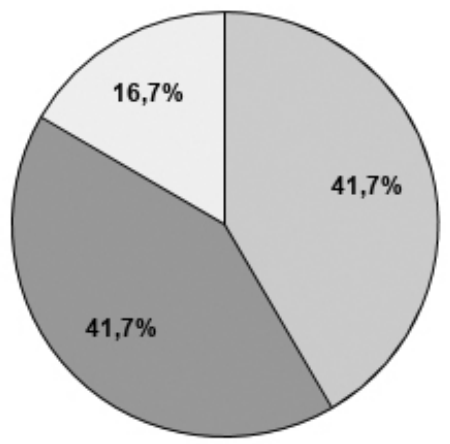

Clinical and epidemiological screening/questionnaire (Q)

Screening + Complementary examination (E) Fast-Track COVID-2019 (F)

Fig. 2: Patient evaluation before dental consultation. Complementary examination mainly consists of temperature assessment. Fast-Track COVID-2019 is one recommended strategy adopted in Brazilian guidelines, in which patients are evaluated by a designated professional before any procedure.

official health administration documents from Brazil; 2 $(10 \%)$ were articles and $2(10 \%)$ others were editorials. Almost all references suggested only maintaining urgency treatments in positive epidemiological areas for the COVID-19 disease (1-13). Only one article suggested to evaluate with each patient and decide if even non-emergency proceedings should be done (14). In relation to patient evaluation before procedures, all articles that mentioned this approach, $72,2 \%(n=13)$, suggested ei- ther an epidemiological and clinical questionnaire or a simple clinical exam (Fig. 2).

Many references also suggested strict infection control actions for the dental office. Those are grouped in Table 1 (2-18). Regarding mouthrinse, 3 references suggested oxidative agents, 1 suggested chlorhexidine (CHX), essential oils, and cetylpyridinium, chloride (CPC), 2 suggested povidone iodine and 3 suggested the use but did not specify which class $(1-3,14)$. Despite those general orientations, there were also more specific recommendations for the use of Personal Protective Equipment (PPE) by $94,7 \%(n=18)$ references (Fig. 3$)$.

\section{Discussion}

The experience of other countries, mainly China, where the COVID-19 outbreak largely affected all social and productive activities, led to the issuing of recommendations for dentists. The reflections regarding dentistry revealed that there is not a real consensus on the provision of dental care during the epidemic of COVID-19, however, some measures are important to protect both patients and professionals. In Brazil the pandemics curve, at present, is still rising and it did not reach its peak of contaminated persons (19). The Brazilian Health Ministry issued a shortlist of measures to be applied during dental assistance, and this workflow has been published in their bulletin and website. This recommendation list does not deal with all aspects of the pandemic's intersections with dentistry, since most mechanisms and consequences of the infection are still largely unknown.

Table 1: Recommendations for the Dental Office.

\begin{tabular}{|l|c|c|}
\hline \multicolumn{1}{|c|}{ General Recommendations } & N & References \\
\hline Extra Attention to Office Cleaning and Staff Protection & 10 & $(4-12)$ \\
\hline Mouthrinse before procedures & 9 & $(5,7-9,13-17)$ \\
\hline Rubber Dam & 8 & $(5,6,8,9,13-15,17)$ \\
\hline Extra Attention to Hand Hygiene & 5 & $(2,8,14,15,18)$ \\
\hline Measures to decrease inter-patient spread in office common areas & 5 & $(5-7,11,18)$ \\
\hline Anti-retraction handpieces / Anti reflux valves & 4 & $(6-8,15)$ \\
\hline Avoid use of high speed handpieces & 4 & $(8-10,14)$ \\
\hline 4 Hands Technique & 3 & $(8,9,13)$ \\
\hline Saliva Ejector & 3 & $(7,11,13)$ \\
\hline Powerfull air/water pump & 2 & $(6,9)$ \\
\hline
\end{tabular}




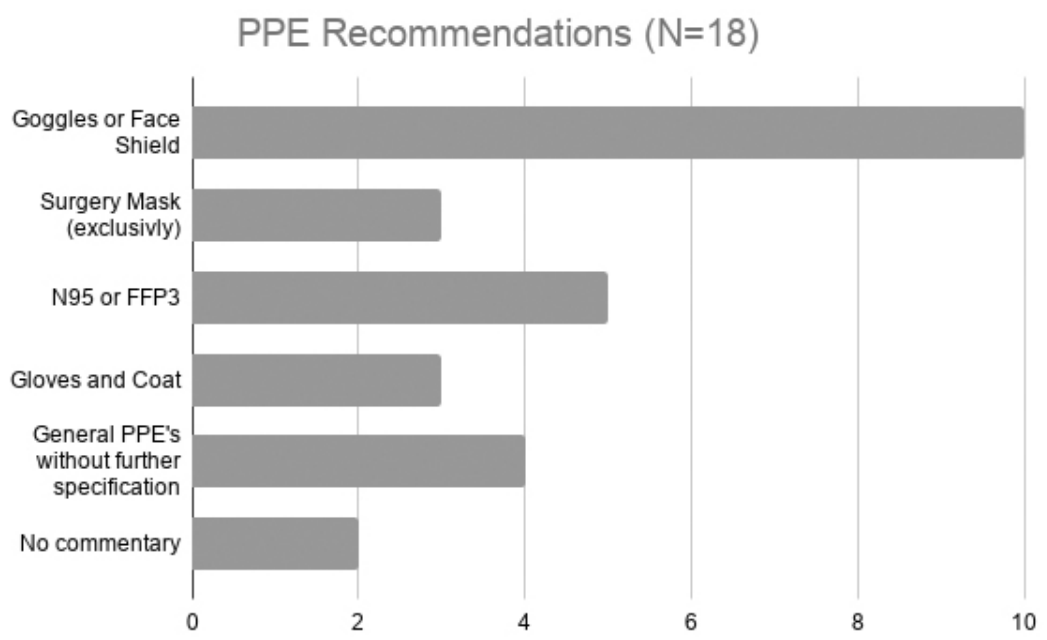

Fig. 3: PPE Recommendations for Dentists. PPE=personal protective equipment.

The American Dental Association (ADA) has been proving to be one of the most active organs in positioning dental practitioners onto the procedures and consequences of assisting patients during the pandemics. This information is added to the recommendations of a number of articles published on the subject (20).

Most publications agree that it is imperative that patients are monitored for COVID-19 infection prior to admission to avoid professionals exposure $(13,16,18,21)$. A precheck triages to measure and record the temperature of every patient must be performed as a routine procedure, using a contact-free forehead (1).

A questionnaire should be used to screen patients with potential infection prior to any procedure (WHO 2020a). The questions most commonly applied to patients are depicted in Table 2. Additionally, patients should be scheduled allowing a large appointment, in order to avoid waiting room overcrowding, and later, a proper office decontamination procedure. Another measure to minimize infection is to postpone health activities in groups such as public campaigns of supervised tooth brushing and Fluor-gel application (21).

The routine practice of dentistry produces high amounts of droplets and aerosols. In this view, professionals should take measures to avoid or minimize procedures in order to reduce this type of risk. The use of saliva ejectors with low or high volume can reduce the production of droplets and aerosols, and the use of rotatory equipment and ultrasonic should be avoided. Additionally, the 4-handed technique is considered important in the control of infection $(1,2,6,7,11)$.

In case of a positive response to any of these questions and body temperature above $37.3^{\circ} \mathrm{C}$ patient should be advised to self-quarantine and the dental professional should report the case to the health authorities. In case of negative responses and body temperature below $37.3^{\circ} \mathrm{C}$, patient can be treated under extra protection measures. When body temperature is elevated above $37.3^{\circ} \mathrm{C}$, in any case, patient must be advised to seek further medical care, and there is no consensus to postpone their treatment, especially in the presence of pain. Therefore, it is very important that dentists work together with the medical network $(6,8)$.

Most authors recommend the use of a mouthrinse to reduce microbial concentration in the oral cavity. Chlorhexidine, which is commonly used as mouthrinse in dental practice, may not be effective to kill 2019-nCoV, but investigations are necessary to prove its' efficacy in

Table 2: Pre-check questionnaire (2).

\begin{tabular}{|c|l|}
\hline \multicolumn{1}{|c|}{ Subject } & \multicolumn{1}{c|}{ Questions } \\
\hline \multicolumn{1}{|c|}{ Patients health } & Have you been febrile within the past 14 days? \\
\cline { 2 - 3 } & Have you had any difficulty in breathing as well as cough during the last 2 weeks? \\
\hline Patients social contacts & $\begin{array}{l}\text { Have you been in areas with documented high incidence of COVID-19? (4) Have } \\
\text { you come into contact with a patient with confirmed }\end{array}$ \\
\cline { 2 - 2 } & COVID-19 infection within the past 14 days? \\
\cline { 2 - 2 } & $\begin{array}{l}\text { Have you recently participated in any meetings or have been in venues with large } \\
\text { number of persons? }\end{array}$ \\
\hline
\end{tabular}


this situation. Some authors point out that $2019-\mathrm{nCoV}$ is vulnerable to oxidation, and recommend preprocedural mouthrinse containing oxidative agents such as $1 \%$ hydrogen peroxide or $0.2 \%$ povidone is recommended, for the purpose of reducing the salivary load of oral microbes, including potential 2019-nCoV carriage (1-3,14). This recommendation lacks consensus and scientific support. Many authors, including the Brazilian Health Ministry recommend the use of rubber dam of dental procedures. A preprocedural mouthrinse would, in theory, be most useful in cases when rubber dam cannot be used $(2,14)$.

Most authors regard the use of goggles and/or face shields as very important to protect dentists during procedures. In fact, this type of protection, as well as masks, gloves and impermeable gowns are essential to avoid cross contamination during any procedure, especially those involving the generation of aerosol $(2,6$ $8,11,21,22)$. Image exams, especially periapical $\mathrm{x}$-rays should also be avoided to prevent the spread of saliva droplets. In case imaging is necessary, a pan-x-ray of CT scans are desirable. Table 3 summarizes professional emergency care during the pandemics, which is the recommendation of most authors $(2,6,7,11,21-22)$.

Finally, special attention is needed for all decontamination procedures in the dental office. Some authors believe that cases suspected or confirmed with COVID-19 should not be treated in the routine dental office, as airborne contamination may occur. Instead, these patients should be referred to dental clinics provided with Nega- tive-pressure treatment rooms. Additionally, the equipment such as the 3-way high-speed rotatory piece, ultrasonic device, and others, should be avoided whenever possible, as they generate high amounts of aerosol. It is well-known that aerosol can spread over the surrounding surfaces and that SARS CoV-2 can remain viable up to 3 days at room temperature (8). Therefore, decontamination of the dental office and surfaces with alcohol at $70 \%$, or $3 \%$ sodium hypochlorite, especially when aerosol has been produced is imperative. Removal and decontamination of filters from air conditioning systems such as high-volume evacuator (HVE) or high-efficiency particulate arrestor (HEPA) is an important step to prevent airborne contamination $(2,16)$. The waste generated by the treatment in the dental offices during the pandemics are considered as infectious, in particular when suspected or confirmed cases of COVID19 were assisted. Therefore, a double-layer yellow colour medical waste package bags and "gooseneck" ligation should be identified and used to dispose all infectious material (7).

Supplementary measures to make dental treatment safer should rise from the further understanding of the pandemics, as many recommendations still lack scientific evidence and the quarantine and present social distancing impact the income of all clinics and dental offices. Certainly, dental assistance will, in future re-evaluate all procedures in the dental office, in face of infectious disease, epidemics and pandemics, to provide information for an increasingly better practice of dentistry in hospitals, clinics and faculties.

Table 3: Summary of the main dental emergencies in need of professional assistance during the COVID-19 pandemics $(2,6-8,11,13,21,22)$.

\begin{tabular}{|c|c|}
\hline Dental emergency & Procedures \\
\hline Routine elective dental treatment & Should be postponed in order to avoid cross-contamination \\
\hline $\begin{array}{l}\text { Carious lesions with endodontics } \\
\text { compromise and pain in adults and } \\
\text { children }\end{array}$ & $\begin{array}{l}\text { 1. pulp exposure and pulp devitalization can be performed using chemo- } \\
\text { mechanical caries removal under rubber dam isolation and a high- } \\
\text { volume saliva ejector after local anesthesia. } \\
\text { 2. } \\
\text { if the use of high-speed handpiece is necessary, patient should be } \\
\text { scheduled as the last appointment of the day. After the use of the high- } \\
\text { speed handpiece or any production of aerosol, a terminal decontamina- } \\
\text { tion should be performed. }\end{array}$ \\
\hline Oral and maxillofacial surgery & $\begin{array}{l}\text { 1. tooth fracture, luxation, or avulsion are dental urgencies and patients } \\
\text { may be assisted upon a previous evaluation. If x-ray is needed, extra- } \\
\text { oral techniques are preferred. } \\
\text { 2. haemorrage and obstruction of upper respiratory tracts following } \\
\text { trauma, tumours, infections should be assisted under the universal } \\
\text { protection protocols. } \\
\text { 3. If the tooth needs to be extracted, absorbable suture is preferred. } \\
\text { 4. facial soft tissue contusion, debridement and suturing should be per- } \\
\text { formed, using absorbable suture. }\end{array}$ \\
\hline Orthodontics and prostodontics & $\begin{array}{l}\text { 1. the dental assistance should include patients with broken devices or } \\
\text { pieces that injure the oral mucosa. } \\
\text { 2. Procedures that generate gagging or coughing should be avoided. }\end{array}$ \\
\hline
\end{tabular}




\section{References}

1. Yang Y, Zhou Y, Liu X, Tan J. Health services provision of 48 public tertiary dental hospitals during the COVID-19 epidemic in China. Clin Oral Investig. 2020;24:1861-4.

2. Yang Y, Soh HY, Cai ZG, Peng X, Zhang Y, Guo CB. Experience of Diagnosing and Managing Patients in Oral Maxillofacial Surgery during the Prevention and Control Period of the New Coronavirus Pneumonia. Chin J Dent Res. 2020;23:57-62.

3. Evans DJR, Bay BH, Wilson TD, Smith CF, Lachman N, Pawlina W. Going Virtual to Support Anatomy Education: A STOP GAP in the Midst of the Covid-19 Pandemic. Anat Sci Educ. 2020;13:279-83.

4. Atendimento odontológico no SUS [Internet]. Brasília-DF Março de 2020. Secretaria de Atenção Primária à Saúde (SAPS). [cited 2020 Jun 10]. Available from: http://189.28.128.100/dab/docs/portaldab/ documentos/COVID_19_ATENDIMENTO\%20ODONTOLOGICO_ SUS APS 20200319 ver001.pdf

5. Ge ZY, Yang LM, Xia JJ, Fu XH, Zhang YZ. Possible aerosol transmission of COVID-19 and special precautions in dentistry. J Zhejiang Univ Sci B. 2020;21:361-68.

6. Prati C, Pelliccioni GA, Sambri V, Chersoni S, Gandolfi MG. COVID-19: its impact on dental schools in Italy, clinical problems in endodontic therapy and general considerations. Int Endod J. 2020;53:723-725.

7. Spagnuolo G, De Vito D, Rengo S, Tatullo M. COVID-19 Outbreak: An Overview on Dentistry. Int J Environ Res Pub Health. 2020;17:2094.

8. Peng X, Xu X, Li Y, Cheng L, Zhou X, Ren B. Transmission routes of 2019-nCoV and controls in dental practice. Int J Oral Sci. 2020;12:9. 9. Saúde SP (Estado) Secretaria da Saúde [Internet]. Covid-19: infection prevention and control measures in health care guidelines for the organization of oral health actions: aps and dental specialty center. [cited 2020 Jun 10]. São Paulo; SES/SP; 2020. 9 p. Available from: 10. Coronavirus-19: fluxo de atendimento odontológico [Internet]. AtendimentoOdontologico-Fluxo-ver002-Final.pdf [cited 2020 Jun 10]. Available from: https://aps.saude.gov.br/ape/corona.https://portalarquivos.saude.gov.br/images/pdf/2020/marco/30/20200330.

11. Khader Y, Al Nsour M, Al-Batayneh OB, Saadeh R, Bashier H, Alfaqih $\mathrm{M}$, et al. Dentists' awareness, perception, and attitude regarding COVID-19 and infection control: A cross-sectional study among Jordanian dentists. JMIR Pub. Health Surveil. 2020;6:e18798.

12. Dave M, Seoudi N, Coulthard P. Urgent dental care for patients during the COVID-19 pandemic. Lancet 2020;395:1257.

13. Meng L, Hua F, Bian Z. Coronavirus Disease 2019 (COVID-19): Emerging and Future Challenges for Dental and Oral Medicine. J Dent Res. 2020;99:481-7.

14. Ather A, Patel B, Ruparel NB, Diogenes A, Hargreaves KM. Coronavirus Disease 19 (COVID-19): Implications for Clinical Dental Care. J Endod. 2020;46:584-95.

15. Napimoga MH, Freitas ARR. Dentistry vs Severe Acute Respiratory Syndrome Coronavirus 2: How to face this enemy. RGO. 2020;68:e20200011.

16. Coulthard P. Dentistry and coronavirus (COVID-19) - moral decision-making. Br Dent J. 2020;228:503-5.

17. Wang Y, Zhou CC, Shu R, Zou J. Oral Health Management of Children during the Epidemic Period of Coronavirus Disease 2019. Sichuan Da Xue Xue Bao Yi Xue Ban. 2020;51:151-4.

18. Sabino-Silva R, Jardim ACG, Siqueira WL. Coronavirus COVID-19 impacts to dentistry and potential salivary diagnosis. Clin Oral Invest. 2020;24:1619-21.

19. Coronavírus Brasil [internet]. [cited 2020 Jun 10]. Available from: https://covid.saude.gov.br/.

20. ADA Coronavirus (COVID-19) Center for Dentists [Internet]. [cited 2020 Apr 28]. Available from: https://success.ada.org/en/practice-management/patients/infectious-diseases-2019-novel coronavirus. 21. Berlin-Broner Y, Levin L. "Dental Hierarchy of Needs" in the COVID-19 Era - or Why Treat When It Doesn't Hurt? Oral Health Prev Dent. 2020;18:95.
22. Guo Y, Yuan C, Wei C. Emergency measures for acute oral mucosa diseases during the outbreak of COVID-19. Oral Dis. 2021;27:737739.

\section{Ethics}

Does not apply.

\section{Funding}

The authors did not receive any funding to perform the present work.

\section{Authors' contributions}

Silvia Vanessa Lourenço: contextualization, data curation, supervision, manuscript preparation.

João Vitor Ziroldo Lopes: methodology, data curation, manuscript preparation.

Gustavo Henrique Pereira Boog: methodology, data curation, manuscript preparation.

Lucas Albuquerque Chinelatto: methodology, data curation, manuscript preparation.

Flavio Carneiro Hojaij: contextualization, data curation, supervision, manuscript preparation.

\section{Conflicts of interests}

All authors declare no conflicts of interests. 